\title{
Professionalism and Knowledgeable Medical Practice of Gynecology
}

\author{
Dimitris Lamproulis* \\ Department of Business Administration, Technological Educational Institution of Thessaly, Greece
}

Submission: April 22, 2019 ; Published: April 29, 2019

*Corresponding author: Dimitris Lamproulis, Department of Business Administration, Technological Educational Institution of Thessaly, Greece

\begin{abstract}
The paper refers to Professionalism as a management's term that intends to place an order into the chaos of Medical Practice and the exercise of gynecology. The investigation points out the vague and uncertain ways that Professionalism is used by many streams of management's research stressing the professionalism's differed semiotics and interpretations. Also, it is underlined the complexity and contradictions that current research imposes upon Medical practice and Gynecology. In particular, it is examined the ethical and ideological roots of professionalism as a Medical practice and its effects on women health. The thesis proposes a new paradigm of understanding professionalism permitting a manyvocal and open interpretation of its nuances which consciously will raise the ethical standards and empathy of doctors towards their colleagues and patients. Thus, it is encouraged professionalism to grow and recreate itself through every day, doctors' and medical staff' practicalities. In that way, it is supported as a personified development of the women health service and care.
\end{abstract}

Professionalism and knowledgeable Medical practice of Gynecology

Medical practitioners today perform excessively complex work. Consequently, they undergo complex and multiple discourses that substantially manifest medical doctors and staff' levels of performances. Characteristically, the latest studies about professionalism illustrate the need of doctors to comply with service marketing standards of hospitality that are delivered to their patients and possible clients [1]. Furthermore, research illustrates that privatized and public medical centers always focus on a service quality performance which aims to offer the best possible deal and overall experience to the treatment of medical illness [2]. Thus, there is a continually growing pressure toward doctors and medical staff to act and behave under a new "regime" of management described "professionalism." However, what exactly is professionalism and how does it affect/impact/ transform the knowledgeable operation and treatment of a doctor towards patients?

The answer varies considerably from a new liberal idea of professionalism to a fixed body of ethical regulations that should strictly bound all doctors and medical staff around the world $[3,4]$. Moreover, yet, it is characteristic that, all known studies of professionalism comprehended it from a dominant logocentric view of reality $[5,6]$. In other words, professionalism counts on generalized prescriptions of behavior that act upon caretakers and medical doctors as iron stretchers that restrict and facilitate their efforts towards the treatment of illnesses and the service of patients. It is not difficult for you to discern that every research on professionalism agrees on adopting a coherent body of rationalized principals and regulations which act as a code of contact between a medical practitioner her or his colleagues and patience $[7,8]$ Hence, the professionalism of Medical practitioners quite literary is considered to fulfill multiple and often contradictory forms of behaviors. For instance, it is quite striking that only a handful of studies realize that the term and the consequences of a professionalism address so many and different layers of work-based arrangements. Thus, professionalism underlines, for instance, the ethical stance/ philosophy and means of a medical behavior, the scope and meaning of illnesses, the doctors' ideology which legitimizes his or her intervention on a patience's disease, the located benchmarking needs for the satisfaction of patients, the kind and quality of training that medical staff perceive from time to time and even the kind of value that is systematically produced to sufferers and their families. It is, also, important to notice that professionalism hardly ever received a clear notion between issues of a woman's health as supposed to a man's or a child's unique medical conditions. Hence, professionalism is apprehended by current literature as a generalized framework of prescriptions avoiding to investigate its claims and the actual practicalities of its premises. Consequently, professionalism is taken for granted as an adequate narrative that provides sufficient and "undeniable" logical explanations about the medical practitioners' acts and forms of behavior toward their colleagues and their patients. 
To the above should be added that professionalism often turns into an audit assessment list of the Human Resource department. Doctors and nursery staff find themselves trapped- suppressed and mishandled- under the immense pressure of senior Medical administrators' teams to follow a plan of preconceptions about Medical practitioners' skills, abilities, and practices. So, is that mean that Professionalism has been elaborated and clearly understood by senior medical practitioners and the medical community? The answer is yes and primary no. The medical centers and community have agreed on a set of predetermined ethical and restrictive forms of actions which aim to protect a patient's vulnerable suffering conditions. They are subject of multiple interpretations and allow many secondary, thirdly and so on parergon acts, methods and practicalities to occur before, during and after the treatment of a patient which are located differently from professionalism. The complexity of professionalism is so extensive that not a single research had achieved to differentiate professionalism from organizational norms, values, practices, and ideologies of medical practice. To further support that argument, Max Weber's [9] well-known thesis about Bureaucracy and Rationalism uses the concept "Professionalism" avoiding quite often to differentiate it from organizational culture and its influence on individuals' thoughts, feelings, and actions within a particular working space. As a result, even today, professionalism is considered to be vaguely interlinked, replaced and overlapped with organizational culture under some mystified ethical conceptualizations and values.

Continuing on the same line of thought, the majority of management studies fail considerably to understand professionalism's multiple and differed layers of genres, styles, and meanings that are used each time that professionalism employed to the resolution of theoretical problems and even to management's practicalities. On the contrary, existent research examines professionalism as a one-dimensional concept avoiding or ignoring its numerous interpreted forms of understandings, the medical practitioners' subjective feelings, imagination and re-orientation towards professionalism and, even, the unique medical conditions in which it is applied. Professionalism still considered to be a stable scientific base of assessing the ethos and knowledgeable qualities of doctors and staff from an internal and external point of view at various medical centers. Thus, professionalism becomes the term that excuses a great load of misconceptions and problematic situations that are summoned during the delivery of medical treatment. Those are overt by media, surprisingly quite often, and refer to unexplained and unexpected medical lacks of care and lack of provisions towards heavy diseased patients. They are also followed by reports about shortages of appropriate medical machinery, hygiene hospital spaces, doctors and medical practitioners' failures, and even to women' mistreatment about the baby delivery care $[10,11]$.

The paramount problematic effect of professionalism to management studies had become so large that actually, the existent claimed objective research has admitted that it is impossible to completely erase the chaotic forces under which any medical practice reconstructs and synthesizes its theories and actions. This is one significant reason that forced the current above research to adopt an upgraded version of examining medical practice without counting only on its mechanics and its hypothetically measurable results. Thus, dominant literature turned to Foucault [12-15] theory realizing that medical practice constitutes of knowledge that underlines certain forms/ manifestations/constructions among medical practitioners and patients. In other words, medical practice is theorized as a puzzle of actions, beliefs, thoughts, and meanings that evolve and step on the type of unequal relations that are built by doctors and patients. Thus, this relative new stream of thought argues that doctors and extensively medical centers fabricate a reality towards disease and a patient that reflects a suffer's weaknesses while he or she seeks the right cure by the doctor's heroic and almost glorified figure. Thus, as if power is a stable and not a constantly fluid, dynamic and changeable relation, practice, reaction, conceptualization, and feeling. Any medical practice such as a woman's health problem does not rely anymore on the past "unassailable" manifested ethical base of doctors' empathy towards an ill deceived human being. However, it counts more on a stable order of reality that emits from the power (as enforcing one's point of view and actions over another) that an institution and its doctors exercise over their patients [16].

Despite that, the specific approach twists considerably even Foucault's parts of his initial theory, most importantly, it reproduces many unanticipated consequences. Firstly, it establishes a preconceived act of medical practice avoiding to examine a broader spectrum of power relations that unfold between patients and medical practitioners. However, even great, it manifests a pre-determined working medical environment in which medical practice omits as insignificant any dynamic, subjective and even unexpected reaction of patients toward the medical care that receive at a time. Actions and thoughts of patients are ignored as of having a limited effect on the overall perceived medical experience. For instance, a woman's health problem to her reproductive process, it is not examined (by the above theory) under the unique circumstances and attributes which could re-orientate the entire medical experience. However, it is faced under the light of a therapeutic regulatory process which dominates and suppresses any differed or unexpected reaction of patients and staff. Consequently, the described above theoretical view places power relations in favor of a doctor and against a patient, and, in a way, that medical practitioners and institutional medical centers to principally motivated by the need to satisfy their financial gains. Besides, the manifold called institutionalized studies, they leave untouched or assume to be an overlap of interest between the medical practice of a doctor and that of a medical institution. As a result, the professionalism of a doctor is found quite literally to overlap with the professionalism that is requested/evaluated and imposed by a medical center upon doctors. 
Therefore, can the management community maintain that professionalism is a highly problematic concept to study medical practice within institutions? In other words, revisiting back to our initial thoughts, what is professionalism and how does influence the knowledgeable performance of medical practitioners towards patients? To answer the above, I believe that is primarily to enclose that professionalism (on its current linguistic forms and conceptualizations) constitutes a highly misinterpreted and ungrounded concept that relies on linguistic constructions that promise fake, irrational and, often, impossible future medical results [17-19]. Professionalism's promises stand frail to every day afresh reality and experience of patients and medical practitioners. It can't sustain its fundamental commitments since; it denies that fantasies, misinterpretations and actors' subjective voices regularly come to add, dismantle and substitute conclusions, affirmations and officially established medical truths about reality. More importantly, the current dominant research on medical professionalism surpasses the fact that the knowledge of medical practice is under many vocal products of a dialogue, dispute, and intervention that is added by any corner of the existent medical practice. Doctors, nurses, patients, medical meetings, press, corporate institutions, communities, and even the entire society speak, interpret and recompose existent medical practices and knowledge. Thus, on adopting a one dimensional and dominant paradigm of experience and medical practice is a highly thorny and even increasingly hazardous practice.

For instance, let's picture the case where a woman delivers a baby, and during that time some rare and unexpected complications occur. Well, how does precisely professionalism manifests itself through doctors, the patient, the staff and the senior administrators of a medical institution? Who can tell with certainty? So under what defined conditions someone assemble her or his suppositions of professionalism? Does the doctor go through a checklist to see if the situation complies with his agreed contractor? Or does her or his best to overcome the problem at that time? Who is in place to define the moral behavior of a doctor at that moment according to her or his conscious and medical knowledge/training/competence? Do the nursery staff decide to seize everything up because they suddenly realize that there is a surprising lack of resources or they continue against all the odds? Does the senior management decide to intervene and provide their solution during those critical moments or stays out of the whole process for the sake of everyone's best interest?

Therefore, theorizing arguments seek to evince a manifestation of professionalism as an appropriate medical narrative. And yet, it constitutes of multi-vocal events, situations, differed perspectives and it is subject to manifold interpretations. Thus, professionalism formulates as an ongoing story-telling among medical doctors, staff, patients, and communities. And its importance, far from objective, depends upon the creators' chosen, at the time, the emphasis of the medical practice. Even more importantly, it is vital that medical care as a constitution of certain knowledge-It is manifested under the manifold and often chaotic conditions, substitutions, and repetitions. It constantly re-invents itself under the influence of new concepts, beliefs, thoughts and even unexpected and rare conditions of work. Hence, it repeatedly re-creates and deconstructs itself under the violent pressure of known and unknown circumstances and meanings towards a new re-constitution and conceptualization of reality [20].

The concept of professionalism roots backs its meaning to Plato's theory of truth and ethics. Also, it is mixed with the ethical dimension of western industrialized societies [21-23]. In other words, the act of medical practice and professionalism are viewed by society as terms that reflect, actualize and reaffirm a hypothetical human true nature which demands its verification each time that Medical practitioners bend over the patient's bed of agony. Nevertheless, it is more complicated. Doctors and health attendants not only are viewed, at the time of suffering, as the super ethical humans that serve a divine truth with a complete lack of self-interest. They are regarded as those who have the power to hold a full (rational) control of the tiniest detail within their accurately organized working environment. In other words, they possess the knowledge-the logic to understand the mechanics of a human's body (to its all ends) and offer the ultimate (medicine) pharmakon- the therapy against any disease. This idealistic (and dialectic) picture of medical staff by western civil society hides meticulously, as Max Weber has revealed, the fact that its ethics bound and count on profit maximization for its members.

In other words, to Plato's and Hegel's dialectic theoretical disappointment, medical doctors and staff, at their current humane state and nature, are quite far from serving the divine truth of order that they are supposed to be destined. Thus, yet, medical professionalism as a term coins the need for a superior ethical behavior and attitude towards patients. And it does that (even Foucault's study) through placing the knowledge of doctors as a moral expected elite's category who can stand high and beyond the rest of society. In other words, well established scientific literature and theory consider Medicine and its practitioners' knowledge to count, be prescribed and manifested upon unverified, highly mythical and fantasizing conceptualizations of medical discipline-and the organizing human reality. However, many agree, that the greatest blow against the spiritual, the Godly driven manifestation of human's moral, it is death itself. Its appearance is always so unexpected shuttering and destroying every bit of the existent, until that time, beliefs and convictions. It so irrationally, provocative and uninterested annihilates our selves, our knowledge and our technologies turning them into a bleak moment of disarray. It cruises over our lives as an invisible and, still, so pragmatic force. It tests, manipulates and torn our efforts, intelligence, and selfassurance. The end, the seize, the destruction comes to testify for a morality that is made by people, men and women and, it is highly unlikely ever to be fully mastered. Death comes to wreck 
every aspect of our civilized communities-purpose of livesand presses over our common existences with extraordinary power. But, death as long as it devastates our rationals, it simultaneously has the potentiality to reconstitute (rise) our creations and ourselves. Thus, it has to be stated that Nietche's [24] conceptualization of will to power swipes underneath us even the last hopes for a supernatural-ethical-formulation of our medical conceptualization of reality.

Nevertheless, an enormous blow to human nature comes from the fact that societies, medical communities, and centers are unable to operate unless doctors and medical professionals sustain high moral and a feeling of empathy towards illness. Thus, I consider a well described (by Plato, Christianity, and Buddism, etc.) ethical medical behavior as a formulation of completion/competence towards a higher conceptualization and understanding of a woman's or a man's health's reality. But, avoiding those management policies and regulations that seek ethical prescriptions to be imposed from an external point of view, and violently on Medical professionals. Medical ethics should be allowed to grow, to be toyed around by medical practitioners offering the opportunity to continually rediscover and re-compile them under novice conceptualizations, conditions of work and health possible illnesses [25]. Thus, it is crucial to settle an open dialogue/dispute/interception and re-examine the human-all vulnerable- conditions under which medical practitioners would be able to construct their ethics and values towards themselves, their colleagues and their patients.

The result of such an approach is multiplied. The professionalism of knowledgeable medical practice should be evoked as a well-elaborated subject and become a point of open communication among its many different parts of the medical community. It is of a paramount effect that the medical practice should move away from the old paradigm of believing in creating superhuman practitioners. Instead, it should focus on its feasible and realistically attributed nature of human beings. It should seek what can be improved now, extracting its own conclusions, as supposed to what the society fantasizes medicine to be towards the constitution of a healthy and unbeatable by fate human. Therefore, I consider that the medical community should turn its attention, also, to examine carefully micro and not only macro cases of health problems. In that way, it would become possible to repeatedly synthesize its conclusions as new shreds of evidence, and medical cases would add new materials and parts of knowledge. Into those medical conditions, gynecology has an upgraded and imperative role to play. It can advance and reveal women's health from a unique point of view avoiding clearly to stand as similar or exactly opposite to a man's or a child's health constitution and condition [26].

Furthermore, it is critical that a knowledgeable medical practice requires individuals and medical communities to seek for realizing the multiple potentialities that are open to human invention and understanding. Seeking for the alleviation of pain and the healing of women, medical practitioners should see women nature as a new window toward the digital age of our times and learn from it. In other words, new technologies, medical discoveries and extended networks of communications should aim to reveal the inefficiencies, misinterpretations, and apprehensions of the distinct creative health of a woman. In that way, it is hoped to be triggered by a constant process of recreating personified forms of female health care and practice. So this approach should find ways of interacting and sharing with the pluralistic developed and differentiated communities of care and health practice around the world. It is not enough just medical staff to shout out wants and wills. It is most critical to come into a discussion understanding their weaknesses as medical practitioners and hold a profound attitude of self-criticism about the ways, means and actions of medical practice and its constitution. Hence, such an approach would benefit doctors and public realizing more substantial than before the limitations of their actions and wills.

\section{References}

1. Davies TH, Nutley MS, Mannion CR (2000) Organisational Culture and Quality of Health Care. Quality in Health Care 9(2): 111-119.

2. Nancarrow AS, Borthwick MA (2005) Dynamic professional boundaries in the healthcare workforce. Sociol Health Illn 27(7): 897-919.

3. DiMaggion JP, Powell WW (2012) The Iron Cage Revisited: Institutinalism Isomorphism and Collective Rationality in Organizational Fields. American Sociological Review 48(2): 147-160.

4. Swick MH (2000) Towards a Normative Definition of Medical Professionalism. Acad Med 75(6): 612-616.

5. Derrida J (1967) writing and Difference. Routledge, Great Britain, UK.

6. Derrida J (1974) Of Grammatology. The Johns Hopkins University Press, USA.

7. Hodgson CD (2002) Disciplining the Professional: the case of project management. Journal of Management Studies 39(6): 803-821.

8. Morris PWG, Grawford L, Hodgon D, Shepherd MM, Thomas J, et al. (2006) Exploring the role of formal bodies of knowledge in defining a profession-The case of project management. International journal of Project Management 24(8): 710-721.

9. Weber M (1946) From Max Weber: Essays in Sociology. Oxford Press, New York, USA.

10. Abernethy AM, Stoelwilder UJ (1995) The Role of Professional Control in the management of Complex Organization. Accounting, Organizations and Society 20(1): 1-17.

11. Noordegraaf M (2011) Risky Business, How Professionals and Professional Fields (Must) Deal with Organizational Issues. Organizational Studies 32(10): 1349-1371.

12. Foucault M (1969) The Archaeology of Knowledge. Oxford, Gallimard, France.

13. Foucault M (1973) The Birth of Clinic. Routledge, London, UK.

14. Foucault M (1978) The History of Sexuality. Random Hous, New York, USA.

15. Foucualt M (1989) The order of Things: An archeology of human sciences. Taylor and Francis, London, UK.

16. Thomas R, Davies A (2005) Theorizing the Micro-politics of Resistance; New Public Management and Managerial Identities in the UK. Public Services Organization Studies 26(5): 683-706. 
17. Wittgestein L (1958) Philosophical Investigations. Blackwell ltd, Oxford, USA.

18. Heidegger M (1961) On the Essense of Truth. Based on the fourth edition of the essay.

19. Heidegger M (1962) Being and time. In: J Macquarrie, E Robinson (Eds), New York, USA.

20. Lamproulis D (2017) A Linguistic Perspective of Knowledge Creation, Sharing and Its Novel Implementation. Journal of Organizational Knowledge Management, p. 23.

21. Weber M (2005) The Protestant Ethic and the spirit of Capitalism. Taylor and Francis, New York, USA.
22. Derrida J (1981) Dissemination. Athlone Press Ltd, Great Britain, UK.

23. Derrida J (1987) The Post Card: From Socrates to Freud and Beyond. The University of Chicago Press, London, UK.

24. Nitzsche F (1967) The Will to Power. Random House Inc, New York, USA.

25. Jung GC (1958) Civilization in Transizion. Princeton University Press, New York, USA.

26. Groddeck VV (2012) Temporizing Identites: How Organizations Construct Identities in a Society of Presents. Journal for Critical Organization Inquiry 10(3): 9-19.

\section{Your next submission with Juniper Publishers will reach you the below assets}

- Quality Editorial service

- Swift Peer Review

- Reprints availability

- E-prints Service

- Manuscript Podcast for convenient understanding

- Global attainment for your research

- Manuscript accessibility in different formats

( Pdf, E-pub, Full Text, Audio)

- Unceasing customer service

Track the below URL for one-step submission https://juniperpublishers.com/online-submission.php 